\title{
Rates of Predation on Mammals by Gombe Chimpanzees, 1972-1975
}

\author{
R. W. Wrangham and E. van ZinnicQ Bergmann Riss \\ University of Michigan
}

\begin{abstract}
Rates of chimpanzee predation on mammals are calculated using data on 75 kills recorded during focal observation in Gombe National Park, Tanzania, from January 1972 to April 1975. The chimpanzees were members of two study communities (Kanyawara, or Northern, and Kahama, or Southern, community), and were observed as focal individuals for $14,583 \mathrm{hr}$ by more than 30 researchers and field assistants working in pairs. The rate of predation by females was too low to allow reasonable estimates. For males, the mean rate of killing during the study period was 0.31 kills per male per $100 \mathrm{hr}(N=17$ males $)$, or 4.65 kills per $100 \mathrm{hr}$ in the two communities. In contrast to results from Mahale Mountains, there was no difference in predation rate between wet and dry seasons. However, predation rates varied over time, increasing by four times between the first three and last four seasons of the sample period. In an average year the 15 adult and subadult male chimpanzees are calculated to have killed 204 prey per year in an area of $16 \mathrm{~km}^{2}$, varying between 99 and 420 prey per year in periods of low and high predation rate. Red colobus were the most frequent prey, followed by bushpig and bushbuck. Predation rates varied greatly on different prey species, and were not related to either the proportion of time spent within $200 \mathrm{~m}$ of male chimpanzees, or to their population densities. In relation to encounter rates and population density, baboons, blue monkeys, and redtail monkeys were killed at a fraction of the rate of red colobus monkeys, which suffered severe mortality from chimpanzee predation. Predation on bushpig and bushbuck also appears to have been high in relation to population density. The amount of food provided by predation is estimated to have averaged $600 \mathrm{~kg}$ per year for chimpanzees in the two communities (totalling 14-17 adult or subadult males, 18-20 adult of subadult females, and about 19 infants or juveniles). This suggests that adult males consumed around $25 \mathrm{~kg}$ of meat per year, although any average figure undoubtedly masks considerable individual variation. Present data suggest that chimpanzees in Gombe and Tai National Park, Ivory Coast, prey on mammals at rates higher than other populations.
\end{abstract}

Key Words: Pan troglodytes; Colobus badius; Papio anubis; Potamochoerus porcus; Predation rate; Food intake.

\section{INTRODUCTION}

Since the first report by Goodall (1963) of predation on mammals, chimpanzees Pan troglodytes have been seen to eat at least 25 species of mammals ranging in size from small rodents (unidentified species, Goodall, 1968; HLadik, 1973) to juvenile bushpigs Potamochoerus porcus estimated to weigh $>20 \mathrm{~kg}$ (Goodall, 1986). Mammalian prey species include ten monkeys (Cercocebus atys, Cercopithecus ascanius, C. diana, C. aethiops, C. mitis, C. sabaeus, Colobus badius, C. polykomos, C. verus, Papio anubis), four prosimians (Galago alleni, G. crassicaudatus, G. senegalensis, Perodicticus potto), four ungulates (Cephalophus monticola, Nesotragus moschatus, Potamochoerus porcus, Tragelaphus scriptus), three rodents (Cricetomys eminil, Funisciurus sp., Protoxerus stangeri), a pangolin (Manis tricuspis), mongoose (Ichneumia albicauda), hyrax (Heterohyrax brucei), and elephant shrew (Rhyn- 
cocyon cernei) (Boesch \& Boesch, 1989; Goodall, 1986; HladiK, 1973; MCGrew et al., 1979; Nishida et al., 1979; Sugiyama, 1981; Suzuki, 1975; Takahata et al., 1984; Teleki, 1981). Additionally, cannibalism of infants has been seen at three sites (Gombe National Park, Tanzania: BygotT, 1972; Mahale Mountains National Park, Tanzania: NishidA et al., 1979; Budongo Forest, Uganda: SuzUKI, 1975). Predation on mammals has been recorded in at least ten populations representing every major type of chimpanzee habitat, from primary forest (Ivory Coast, BoEsCH \& BoESCH, 1989; Liberia, ANDERSON et al., 1983; Uganda, SuzUKI, 1975) to the dry woodlands in the extreme east (Ugalla, Tanzania: NisHIDA, 1989) and west of their geographic range (Mt. Assirik, Senegal: MCGREw et al., 1979). In many field studies predation has not been recorded (e.g. Albrecht \& DUNNETT, 1971; Azuma \& Toyoshima, 1962; De Bournonville, 1967; Dupuy, 1970; Ghiglieri, 1984; IZAWA, 1970; IzaWA \& ITANI, 1966; Jones \& SABATER Pí, 1971; Kano, 1971; KoRTLANDT, 1962; NisSEN, 1931; ReYNolds \& ReYNOLds, 1965). However in most of these there was little direct observation of chimpanzees, and predation has since been reported in several of these study areas (e.g. Kibale Forest, G. I.-BAsuta, pers. comm.). At present there is no good evidence of a chimpanzee population which does not at least occasionally eat mammals.

Predation on mammals is not the only source of animal food. Mammals may also be scavenged (HASEGawa et al., 1983) or pirated from other predators (MorRis \& GoOdaLL, 1977). Birds and their eggs are occasionally taken also (e.g. $6.4 \%$ of 409 vertebrate prey in Gombe, Goodall, 1986, Table 11.2). There is one fecal record of a snake-skin (MCGrEw et al., 1978). In some populations insects constitute important prey (e.g. McGrew, 1979; UeHARA, 1986). Mammals are undoubtedly killed and eaten much more commonly than other vertebrates, however.

Despite the numerous reports of predation on mammals by chimpanzees, its ecological significance, both to different chimpanzee populations and to prey species, is poorly understood because of the difficulty of estimating how often it occurs. Previous estimates have relied largely on the number of predations observed in a given time, without allowing for unseen episodes. For instance, TAKAHATA et al. (1984) noted that the frequency of successful cases of predation appeared to be higher in Mahale ( 42 observed in 34 months, i.e. 14.8 per year) than in Gombe ( 71 in 69 months, i.e. 12.3 per year). However because these figures are minimal estimates the comparison is invalid. For instance in Gombe the true rate appears to be at least five times greater than the minimal estimate (below).

The problem of unobserved predations is considered to be less severe in Tai National Park in the Ivory Coast because the nine adult males of the Tai community regularly travel together. Since males also kill more often than females $(81.6 \%$ of 38 observed kills were by males), BoESCH and BOESCH (1989) considered that by following the core group of males they "missed few hunts performed by the central animals." The BoEsCHS observed 100 hunts in 299 days. Based on a success rate of $60.0 \%$ (81 kills in 135 hunts observed over seven years), this suggested that the community (79 individuals living in $27 \mathrm{~km}^{2}$ ) killed a minimum of 73.2 prey per year.

The Tai data indicate a predation rate comparable to a previous estimate from Gombe that attempted to account for unobserved predations. Data over a three-year period (August 1970 to August 1973) suggested an average annual rate of 63 predations, including piracy of carcasses from baboons, in an area of $16 \mathrm{~km}^{2}$ (i.e. the community ranges of 31 adolescent and adult chimpanzees in two adjacent communities) (WRANGHAM, 1975). This figure was based on 34 predations attended by focal individuals during 10,397 observation hours. The 
number of unobserved predations was estimated from data on the number of individuals attending each predation.

A better method for estimating rates of predation is to sum observed rates of killing by focal individuals, because it incurs fewer assumptions about the behavior of individuals not present at kills (e.g. it avoids the assumption that within age-sex classes individuals are equally likely to attend predations). Between January 1972 and April 1975 the intensity of observation in Gombe was sufficiently high that kill rates can be calculated. In this paper, therefore, we use an improved method to estimate the rate of predation on mammals. The aim of doing so is to provide a firmer basis for comparing predation rates among chimpanzee populations, to obtain a clear picture of the significance of meat in the diet of chimpanzees, and to understand the impact of chimpanzee predation on prey species. Such information should ultimately aid in reconstructing the diets of extinct apes such as australopithecines.

In the first part of the paper we examine predation frequencies regardless of prey species, and in the second we analyze species differences in the number killed. Cases of piracy from baboons, which account for approximately half of the cases when chimpanzees eat bushbuck fawns Tragelaphus scriptus (GoODALL, 1986), are included as predations. Infanticide is excluded from the analysis. Chimpanzee predatory behavior at Gombe has been described and reviewed in detail by Goodall $(1968,1986)$ and TeleKr $(1973,1981)$. Six species of medium-sized mammals have been killed regularly since 1960 (red colobus Colobus badius, redtail monkey Cercopithecus ascanius, blue monkey Cercopithecus mitis, baboon Papio anubis, bushbuck, and bushpig).

\section{METHODS}

The study site was described by Clutton-Brock and Gillett (1979) and Goodall (1986). Observations were made of two adjacent communities of habituated chimpanzees whose behavior and ecology were described by Goodall (1986). From 1972 to 1975 the Kasekela (Northern) community had 13-14 independent females, 9-10 males, and about 13 infants or juveniles; the Kahama (Southern) community had 5-6 females, 5-7 males, and about 6 young. The principal data analyzed here were collected from January 1972 to April 1975 (when at least one of us was working in Gombe) by more than 30 researchers and field assistants working in pairs. Each pair recorded the behavior of a single "focal individual" for periods from $1 \mathrm{hr}$ to several days continuously (see Goodall, 1986 for a detailed description of methods). Focal individuals were selected at random with respect to the timing of predation events, i.e. individuals were not selected as focals during attempted predations. A total of 14,583 focal observation hours were collected and are analyzed in this paper. Additional data on records of predation come from the records of the Gombe Stream Research Center from 1968 to 1975.

\section{RESULTS}

\section{KILL FreQUenCY}

Between January 1972 and April 1975, 80 prey animals were seen to be killed or eaten, including records when no chimpanzee was a focal individual. Focal individuals killed or participated in the killing of 30 prey. Six prey were killed by joint action between focal and 
Table 1. Rates of killing and predation attendance by males.

\begin{tabular}{|c|c|c|c|c|c|c|c|}
\hline & & $\begin{array}{l}\text { Hours as } \\
\text { focal male }\end{array}$ & Focal kills & $\begin{array}{l}\text { Focal kills } \\
\text { per } 100 \mathrm{hr}^{33}\end{array}$ & $\begin{array}{l}\text { Predations } \\
\text { by non- } \\
\text { focal subject }\end{array}$ & $\begin{array}{l}\text { Predations } \\
\text { per } 100 \mathrm{hr}^{5}\end{array}$ & $\begin{array}{l}\text { Kills } 1968 \\
1975^{6}\end{array}$ \\
\hline \multirow[t]{10}{*}{ Kasekela: } & Figan & 1698 & 7.3 & 0.43 & 7 & 0.41 & 15.5 \\
\hline & Evered & 680 & - & - & 5 & 0.74 & 3 \\
\hline & Faben & 616 & - & - & 5 & 0.81 & 4 \\
\hline & Goblin & 570 & 0,3 & 0.05 & 1 & 0.18 & 2 \\
\hline & Satan & 465 & 1.0 & 0.22 & 2 & 0.43 & 5 \\
\hline & Humphrey & 434 & 2.0 & 0.46 & 5 & 1.15 & 5 \\
\hline & Hugo & 382 & - & - & 1 & 0.26 & 5 \\
\hline & Sherry & 365 & 2.5 & 0.68 & 1 & 0.28 & 4 \\
\hline & Mike & 278 & 0.5 & 0.18 & - & - & 4 \\
\hline & Jomeo & 223 & 3.0 & 1.35 & 1 & 0.45 & 8 \\
\hline Kasekela males & & 5711 & 16.6 & & 28 & & 55.5 \\
\hline \multirow[t]{7}{*}{ Kahama: } & Sniff & 582 & 8.3 & 1.43 & 3 & 0.52 & 18 \\
\hline & Goliath & 199 & - & - & - & - & 2 \\
\hline & Charlie & 192 & 1.0 & 0.52 & 1 & 0.52 & 4.5 \\
\hline & Godi & 150 & - & - & - & - & 2 \\
\hline & Hugh & 94 & - & - & - & - & 1 \\
\hline & Willy-Wally & 89 & - & - & 1 & 1.12 & 3.5 \\
\hline & $D e$ & 81 & - & - & - & - & 0 \\
\hline Kahama males & & 1387 & 9.3 & & 5 & & 31 \\
\hline
\end{tabular}

1) Focal observation hours from January 1972 to April 1975 ; 2) No. of animals killed by male while being observed as a focal individual, January 1972 to April 1975. Decimals show responsibility for kill was shared with one or two others; 3 ) "focal kills" $\times 100$ divided by "hours as focal males;" 4) No. of predations attended by focal male when the prey was killed by a non-focal male or female, either in the male's or another party, during focal observation January 1972 to April 1975; 5) "predations by non-focal subject" $\times 100$ divided by "hours as focal male;" 6) No. of animals killed by male during all observations, whether focal or non-focal, from March 1968 to May 1975.

non-focal individuals, such as one male restraining the victim while a second bit its head. The remaining 24 were killed by the focal individual only, though others often joined in the pursuit. To estimate the number of prey killed per year, kills are scored as 1 if made only by the focal individual, and as 0.5 or 0.3 if one or two others assisted. At two predations the focal individual killed twice, and these were scored as two prey each time. By these criteria males killed 25.9 animals during $7,098 \mathrm{hr}$, and females 0.5 animals in 7,485 hr. These figures give overall rates of 0.36 (per male) and 0.01 (per female) kills per 100 observation hours. During the same period males attended a mean of 0.40 predations per $100 \mathrm{hr}$ where the prey was killed by another chimpanzee (Table 1).

The estimate of the overall kill rate is subject to bias due to uneven sampling of communities, individuals, seasons, and times of day. Since females killed so rarely, the influence of these variables is examined using only the data on males.

First, the average kill rate by males appears to be higher in the Kahama community $(9.3$ kills in $1,387 \mathrm{hr}$, i.e. $0.67 / 100 \mathrm{hr}$ ) than the Kasekela community $(16.6$ kills in $5,711 \mathrm{hr}$, i.e. $0.29 / 100 \mathrm{hr}$ ) (Table 1). Because the Kahama males contribute relatively few observation hours, this difference means that the combined rate of $0.36 \mathrm{kills} / 100 \mathrm{hr}$ could be an underestimate. However, the high estimate for the Kahama rate is due primarily to one individual (Sniff). The mean kill rates by males within the communities are relatively close (Kasekela mean rate 0.34 kills $/ 100 \mathrm{hr}$, Kahama $0.28 \mathrm{kills} / 100 \mathrm{hr}$ ). Provided that mean kill rates are used, therefore, rather than the total number of kills observed by focal individuals within each community, the data can justifiably be pooled. 
Second, different individuals were focal subjects for different amounts of time. In each community the male with most time as focal individual killed at a high rate (Table 1), suggesting the possibility that the overall rate is an overestimate. However there is no consistent relationship between individual kill rates and number of observation hours (Spearman $\rho=$ $0.29, N=17$, n.s.). Uneven sampling of individuals appears not to have had important effects, therefore. Nevertheless it is clearly safest to use the mean rate of killing across individuals as the basis for estimating the total rate of prey capture by the two communities.

Though Table 1 shows considerable individual differences in kill rate, this is certainly at least partly due to the small sample size. All males except $D e$, who was seen least often, were observed killing prey at least once between 1968 and 1975 (Table 1). At present, therefore, there is no firm evidence of long-term individual differences in the frequency of killing. However, Sniff's high rate is certainly suggestive (Table 1). Furthermore, Goodall (1986) reported for the Kasekela community that there were statistically significant individual differences in the proportion of red colobus hunts that were successful. From 1976 to 1981 Figan and Sherry had the highest rates (4.2 and 3.4 hunts per kill, respectively, compared to a mean of 7.5 hunts per kill for five other males). Since Figan and Sherry had high rates of predation in our 1972-1975 sample (Table 1), it is possible that these reflect real differences in individual kill rates.

Third, kill rates varied over time. TAKAHATA et al. (1984) showed that in Mahale the proportion of chimpanzee feces containing mammalian remains was significantly higher in the dry season $(1.4 \%, N=2,837$, May-October) than in the rainy season $(0.5 \%, N=1,380$, November-April). Since in our sample more observation hours were accumulated during dry season months, TAKAHATA et al.'s conclusion raises the possibility that overall rates are overestimated by using data pooled from both seasons. Kill rates were therefore calculated separately for wet (November to April) and dry seasons (May to October). [GoodALL (1986) showed that total mean rainfall and number of rainy days per month show little overlap between these periods.] Table 2 shows that in Gombe, by contrast to Mahale, there is no indication that kill rates are higher in the dry season.

However, the observed kill rate changed over time, rising after the 1973 dry season and staying high for at least 18 months (Table 2). Comparing the number of kills in relation to the total number of observation hours, the rate of killing was significantly higher from November 1973 to April 1975 than from January 1972 to October $1973\left(\chi^{2}=7.95, d f=1\right.$, $p<0.01$ ). If individual kill rates increased after October 1973, the number of predations

Table 2. Variation in rates of predation over time.*

\begin{tabular}{llcclcc}
\hline & Season & $\begin{array}{l}\text { Observation } \\
\text { hours }\end{array}$ & Focal kills & $\begin{array}{l}\text { Focal kills/ } \\
100 \text { hr }\end{array}$ & $\begin{array}{l}\text { Predations } \\
\text { by non-focal } \\
\text { subject }\end{array}$ & $\begin{array}{l}\text { Predations } \\
\text { per } 100 \text { hr }\end{array}$ \\
\hline Jan. 1972-Apr. 1972 & Wet & 433 & 1 & .23 & 1 & .23 \\
May 1972-Oct. 1972 & Dry & 1243 & 2 & .16 & 3 & .24 \\
Nov. 1972-Apr. 1973 & Wet & 895 & 0.8 & .09 & 2 & .22 \\
May 1973-Oct. 1973 & Dry & 1295 & 1.5 & .12 & 7 & .54 \\
Nov. 1973-Apr. 1974 & Wet & 833 & 6.3 & .76 & 6 & .72 \\
May 1974-Oct. 1974 & Dry & 1513 & 9.3 & .61 & 7 & .46 \\
Nov. 1974-Apr. 1975 & Wet & 886 & 5 & .56 & 7 & .79 \\
Jan. 1972-Apr. 1975 & All & 7098 & 25.9 & & 33 & \\
\hline
\end{tabular}

*Data are from all focal observations of Kasekela and Kahama males, January 1972 to April 1975. 1) Focal observation hours summed across all males. Focal kills etc. are as in Table 1, except that data are summed across all males. 
attended by focal males when the prey was killed by a non-focal chimpanzee can also be expected to increase. The number of these non-focal predations is shown in Table 2. Although there is the expected rise in the number of predations (mean non-focal predations attended per $100 \mathrm{hr}=0.31$ from January 1972 to October 1973, vs. 0.66 from November 1973 to April $1975)$, the difference is not quite significant $\left(\chi^{2}=3.15, d f=1, p<0.1\right)$. However the number of all kills observed during focal observations (i.e. made both by focal and nonfocal individuals) shows a clear increase after October $1973\left(\chi^{2}=12.33, d f=1, p<0.001\right)$.

The rise in kill rate after October 1973 means that if seasons were sampled unevenly, the estimate of the average predation rate from January 1972 to April 1975 could have been biassed. However there is no tendency for the number of observation hours to be correlated with the kill rate (Spearman $\rho=-0.21, N=7$, n.s.). Variation in the intensity of observation therefore does not appear to have influenced the estimate of the average kill-rate over this period.

Fourth, observation hours were distributed unevenly over the day, there being fewer in the early morning and late evening. However Table 3 shows that the proportion of kills recorded at different times of day closely reflects observation effort $(r=0.91, d f=6, p<0.01)$. There is therefore no indication that any systematic biases were incurred from the greater intensity of observation in the middle of the day.

Thus although the estimate of the rate of killing must be treated cautiously because of its variability between years, it does not appear to have been biassed by uneven sampling. This allows us to calculate the number of kills made per year. From January 1972 to April 1975 the mean kill rate among the 17 males of both communities was 0.31 prey per $100 \mathrm{hr}$ (s.d. = 0.45) (data from Table 1). However, this was not consistent. From January 1972 to October 1973 the mean kill rate across seasons was 0.15; from November 1973 to April 1974 it was 0.64 (data from Table 2). Accordingly, we take the mean kill rate per male to be 0.31 prey per $100 \mathrm{hr}$, ranging between periods of low and high kill rate from 0.15 to 0.64 .

The mean time spent by Gombe males between night-nests is $12 \mathrm{hr}$ per day (WRANGHAM, 1977). The average male, therefore, killed 13.6 prey per year $($ i.e. $0.0031 \times 12 \times 365$ ), varying between years from 6.6 to 28.0 . The number of adult males fluctuated by growth and death, averaging 15 per year. This means that from 1972 to 1975 males in the two communities are estimated to have killed an average of 204 prey annually (i.e. $13.6 \times 15$ ), varying between 99 and 420 prey in periods of low and high predation rates.

\section{Species Composition of PreY}

During focal observation from 1972 to 1975,75 prey animals were identified. Of these, $76.0 \%$ were red colobus monkeys, $17.3 \%$ bushpig, and three species contributed the remaining $6.6 \%$ (Table 4). This shows clearly that red colobus dominated chimpanzees' mammalian diet during this period, as reported by Goodall (1986) (see Tables 4 \& 5).

Table 3. Diurnal variation in predation occurrence and observation hours.

\begin{tabular}{|c|c|c|c|c|c|c|c|}
\hline Time & $6-8$ & $8-10$ & $10-12$ & $12-14$ & $14-16$ & $16-18$ & $18-20$ \\
\hline $\begin{array}{l}\% \text { kills }^{12} \\
\text { observations }\end{array}$ & $\begin{array}{l}2.7 \\
6.7\end{array}$ & $\begin{array}{l}21.6 \\
16.0\end{array}$ & $\begin{array}{l}18.9 \\
19.8\end{array}$ & $\begin{array}{l}23.0 \\
17.3\end{array}$ & $\begin{array}{l}20.3 \\
16.8\end{array}$ & $\begin{array}{l}10.8 \\
160\end{array}$ & $\begin{array}{l}2.7 \\
7.4\end{array}$ \\
\hline
\end{tabular}

1) Proportion of kills occurring within each time block. $N=49$ kills, i.e. all kills by adult males for which the time of killing was recorded during focal observations, August 1970 to April $1975 ; 2$ ) distribution of focal male observation hours, obtained by sampling 600 focal observations from August 1970 to April 1975. 
Table 4. Proportion of different mammals as prey.

\begin{tabular}{|c|c|c|c|c|c|c|c|}
\hline & \multicolumn{2}{|c|}{ Jan. 1972-Apr. 1975} & \multicolumn{3}{|c|}{$1960-1971$} & \multicolumn{2}{|c|}{$1972-1981$} \\
\hline & $N$ & $\%$ & $N$ & $\%$ & & $\bar{N}$ & $\%$ \\
\hline \multicolumn{8}{|l|}{ Primates } \\
\hline Red colobus & 57 & 76.0 & 18 & 24.7) & & 203 & 65.5 \\
\hline Baboon & 1 & 1.3 .78 .6 & 17 & $23.3\}$ & 50.7 & 8 & $2.6\} 69.7$ \\
\hline Redtail/blue monkey & 1 & $1.3)$ & 2 & 2.7) & & 5 & $1.6)$ \\
\hline \multicolumn{8}{|l|}{ Ungulates } \\
\hline Bushpig & 13 & $17.3\}_{213}$ & 15 & $20.5\}$ & 342 & 51 & $16.5) 291$ \\
\hline Bushbuck & 3 & 4.\}^{21.3}$ & 10 & 13.7 & 34.2 & 39 & $12.6^{29.1}$ \\
\hline Rodent & 0 & 0.0 & 0 & 0.0 & & 2 & 0.6 \\
\hline Unidentified & 0 & 0.0 & 11 & 15.1 & & 2 & 0.6 \\
\hline All mammals & 75 & 99.9 & 73 & 100.0 & & 310 & 100.0 \\
\hline Source & \multicolumn{2}{|c|}{ This study } & \multicolumn{3}{|c|}{$\begin{array}{l}\text { GoODALL (1986: } \\
\text { Table 11.2) }\end{array}$} & \multicolumn{2}{|c|}{$\begin{array}{l}\text { GoODALL (1986: } \\
\text { Table 11.2) }\end{array}$} \\
\hline
\end{tabular}

$N:$ Total number of prey identified (Jan. 1972 to Apr. 1975: kills during focal observations only; other samples: all kills recorded); \%: percentage of mammalian prey.

Table 5. Annual variation in the proportion of red colobus kills.

\begin{tabular}{|c|c|c|c|c|}
\hline \multirow{2}{*}{$\frac{\text { Source }}{\text { Year }}$} & \multicolumn{2}{|c|}{ GoodALL (1986: Table 11.2) } & \multicolumn{2}{|c|}{ This study } \\
\hline & $N$ & $\%$ & $N$ & $\%$ \\
\hline $1960-1963$ & 4 & 26.7 & & \\
\hline 1964-1967 & 6 & 25.0 & & \\
\hline $1968-1969$ & 3 & 15.8 & & \\
\hline $1970-1971$ & $\ddot{5}$ & 33.3 & & \\
\hline $1972-1974$ & 42 & 62.7 & & \\
\hline 1972 & & & 4 & 57.1 \\
\hline 1973 & & & 17 & 73.9 \\
\hline 1974 & & & 25 & 73.5 \\
\hline 1975 & 18 & 66.7 & 11 & 100.0 \\
\hline 1976 & 19 & 59.4 & & \\
\hline 1977 & 37 & 69.8 & & \\
\hline 1978 & 32 & 68.1 & & \\
\hline 1979 & 25 & 71.4 & & \\
\hline 1980 & 16 & 72.7 & & \\
\hline 1981 & 14 & 51.9 & & \\
\hline $1960-1981$ & 221 & 57.7 & & \\
\hline 1972-1975 & & & 57 & 76.0 \\
\hline
\end{tabular}

$N$ : Total number of prey identified; \%: percentage of mammalian prey (excluding infanticide).

This might be considered unrepresentative because two earlier reports from Gombe suggested that red colobus were less frequently taken as prey. GooDALL (1968) found that red colobus made up only $28.6 \%$ of 35 identified prey, while TELEKI (1973) reported that they constituted $19.0 \%$ of a different sample of 21 kills. Although this possibly reflects a real change in the chimpanzee prey profile, it is more likely due to biases in the earlier samples: observations during the 1960's were not primarily made on focal individuals. In particular, many predations recorded before the early 1970's were discovered ad lib., because they happened close to the artificial feeding area, where most observation occurred. In the ad lib. observations red colobus made up a smaller proportion of prey (e.g. $28.6 \%, N=21$ ) than during focal observations (55.2\%,N=29, data from August 1970 to August 1973). The difference is easily explained by the fact that the habitat close to the artificial feeding area was used relatively little by red colobus, but heavily by baboons. 
Table 6. Estimated numbers of prey killed per year.

\begin{tabular}{lrrrrr} 
& \multicolumn{2}{c}{ Predation rate } & & \\
\cline { 2 - 3 } & Low & Average & High & & \% time within $200 \mathrm{~m}^{12}$ \\
\hline Primates & & & & \\
Red colobus & 64.8 & 133.6 & 275.1 & 0.68 \\
Baboon & 2.6 & 5.3 & 10.9 & 4.30 \\
Redtail/blue monkey & 1.6 & 3.3 & 6.7 & 0.36 \\
Ungulates & & & & \\
Bushpig & 16.3 & 33.7 & 69.3 & 0.15 \\
$\quad$ Bushbuck & 12.5 & 25.7 & 52.9 & 0.07 \\
Rodent & 0.6 & 1.2 & 2.5 & $?$ \\
Unidentified & 0.6 & 1.2 & 2.5 & $?$ \\
\hline
\end{tabular}

Estimated numbers of prey killed by Kasekela and Kahama males are shown using data on kill rates from January 1972 to October 1973 ("Low predation rate"), November 1973 to April 1975 ("High predation rate"), and averaged from January 1972 to April 1975 ("Average predation rate"). Prey profile is taken from Goodall's (1986) data for 1972 to 1981 (see Table 4). 1) Proportion of 5-min points on which the species was visible or audible within $200 \mathrm{~m}$ of a focal male chimpanzee $(N=11,9425$-min points, data collected by R.W.W. from May 1972 to September 1973).

Since the early 1970"s, when focal observations became the primary method of data collection, the proportion of red colobus as mammalian prey has remained high. In GooDALL's data from 1972 to 1981 , for example, the mean proportion across years was $65.3 \%$ ( $\pm 7.0 \%$ ), compared to $25.2 \%( \pm 7.2 \%$ ) before 1971 (Table 5). Even though these data include a few non-focal observations, therefore, the large sample size and low interannual variation from 1972 to 1981 means that data from this period offer the safest estimate of the longterm prey profile. We therefore use it to estimate the impact of chimpanzees on particular prey species. The proportions of each species as prey from 1972 to 1981 are shown in Table 4.

To obtain the number of each species killed annually, we use the average of 204 kills per year, together with the number of kills estimated for periods of low (99 kills) and high predation rate (420 kills). Results indicate that in an average year chimpanzees of the two communities killed 134 red colobus, rising to 275 during periods of high predation rate (Table 6). Bushpig and bushbuck also suffered substantial mortality, up to 69 and 53 killed annually. The total kills of other prey species are relatively trivial.

Table 6 also shows the proportion of time that male chimpanzees spent in contact with prey species, i.e. when the observer heard or saw the species within $200 \mathrm{~m}$ of the focal male. Baboons were in proximity most often. (The value in Table $6,4.30 \%$, is exaggerated by inclusion of habituated baboons: unhabituated baboons, which tended to leave after seeing observers, were present for $1.81 \%$ of chimpanzees' time, i.e. still more than twice as much as any other species.) Red colobus, by contrast, were recorded for only $0.68 \%$ of time. It is clear that in proportion to the amount of time spent in proximity, red colobus were more vulnerable than baboons to predations by chimpanzees. Baboons were evidently able to defend themselves more effectively (GoOdALL, 1986).

Unfortunately population size is not well known for any of the prey species. Figures in Clutton-Brock (1972) suggest a population density in 1969 of approximately $20 / \mathrm{km}^{2}$ for red colobus, $30 / \mathrm{km}^{2}$ for baboons, and $11 / \mathrm{km}^{2}$ for redtail and blue monkeys combined. However the estimates were not based on censuses. Bushpig are difficult to count because of their nocturnal habits and variable group size, but they appeared to be no more abundant than baboons, i.e. $<30 / \mathrm{km}^{2}$. Bushbuck densities have been recorded elsewhere as high as $20 /$ $\mathrm{km}^{2}$ in Chobe National Park, Botswana (C. D. Simpson, pers. comm.). By comparison to 
Chobe (R. W. W., pers. obs.), our guess is that in Gombe their density was no more than $6 / \mathrm{km}^{2}$. The combined community ranges of the Kasekela and Kahama community ranges was $16 \mathrm{~km}^{2}$ (WRANGHAM, 1975; GoODALL, 1986), so the average annual kill density was $204 / 16=12.7 \mathrm{kills} / \mathrm{km}^{2}$ (range 6.2-26.2). Using the prey proportions reported for 1972 to 1981 (Table 4), the above figures yield estimates for average annual proportions of the population density killed as follows: red colobus $41.6 \%$; baboon $1.1 \%$; redtail and blue monkey (combined) $1.8 \%$; bushpig $7.0 \%$; and bushbuck $26.7 \%$. (The bushbuck figure includes predation by both baboons and chimpanzees.) These should not of course be taken as accurate estimates. We present them solely to indicate their order of magnitude. They suggest that chimpanzees have substantial demographic effects on red colobus and possibly bushbuck, whereas their effects on baboons, redtails, and blue monkeys appear trivial. Bushpig mortality may also be importantly affected by chimpanzee predation.

\section{DISCUSSION}

\section{Predation Rates at Gombe and in Other Chimpanzee Populations}

Out of 19 species of non-human primates observed to hunt and/or eat mammals in the wild, only baboons and chimpanzees eat prey larger than about $0.5 \mathrm{~kg}$ (BUTYNSKI, 1982). Present data also indicate that hunting of mammals, or of vertebrates in general, is more common by baboons and chimpanzees than by other primates (BUTYNSKI, 1982). Even among these species, however, the frequency of predation is normally too low to allow it to be estimated confidently.

Our data indicate that the rate of predation by Gombe chimpanzees over as long as four years is substantially higher than previously supposed (BUSSE, 1977; TeLEKI, 1981). Our estimate of an average of 204 kills per year is more than three times higher than the only previous estimate (WRANGHAM, 1975) and eight times higher than the figure from which BUSSE (1977) suggested, on the basis of observed predations only, that chimpanzees killed 4-6\% of the red colobus population annually. Its validity was tested by examining the effects of uneven sampling of communities, individuals, period, and time of day. No major effects were found, and we conclude that it gives a good approximation of the average rate of predation from 1972 to 1975 . The reason that it is higher than the WRANGHAM (1975) estimate of 63 predations per year from August 1970 to August 1973 may be partly due to improved methodology in the present analysis. However there is a clear indication that predation rates were relatively low from January 1972 to October 1973 (Table 2), so that the revised estimate in this paper is probably also a result of including data from a period when predation rates were relatively high.

The period of high predation rate (November 1974 to April 1975) is too short to justify strong confidence in its long-term significance. Nevertheless, although predation rates cannot be calculated precisely in subsequent years, the rate from 1972 to 1975 does not appear to have been higher than normal. Thus, the number of recorded predations from 1976 to 1981 was consistently high (mean $=35.8$ per year, range $26-53$ ), compared to a mean of 7.5 for 1970 to 1971 , and 23.5 for 1972 to 1975 (calculated from Table 11.2 in Goodall, 1986). Although the high figures for 1976 to 1981 may have been due to an increase in observation effort, figures given by GooDALL (1986) for the number of observation hours 
from 1978 to 1981 suggest otherwise. Thus, the mean number of predations recorded per year (in all contexts) compared to the number of focal male observation hours was 2.87 per $100 \mathrm{hr}$ from 1978 to 1981 , compared to 0.85 per $100 \mathrm{hr}$ for 1972 to April 1975 . Hence, predation rates may actually have increased after 1975 . If our calculations of total predation rates are biassed, therefore, the conservative conclusion is that they are underestimates of the long-term rate.

The reasons for long-term changes in predation rate are obscure. There is no indication that artificial feeding has had any effect on the rate of predation except in increasing the number of baboon kills over the period of heavy banana provisioning in 1968 and 1969 (Table 4; Wrangham, 1974; Teleki, 1981; Goodall, 1986). Possible factors influencing predation rates include changes in individual composition (and predatory tendency) within the community, changes in size of parties (sub-groups), and changes in prey availability (TELEKI, 1981; Goodall, 1986).

In our sample females killed at a very low rate. All studies on chimpanzees concur that females kill less often than males, but GoodalL (1986) showed that after 1976 females were regularly seen to kill red colobus, bushbuck, and bushpig. Goodall (1986) suggested that the rate of killing by females in the present sample may have been underestimated because focal observations on females tended to be shorter than those on males.

Our estimate for Gombe is certainly not representative of other chimpanzee populations. However, it is rather similar to the estimate of annual kill rates for Tai chimpanzees (BoESCH \& BoESCH, 1989). Thus, if 73.2 kills are made in Tai per year, of which $81.6 \%$ are made by nine males (see Introduction), the number of kills per male is $(73.2 \times 816 / 9)=6.6$ per year, compared to 13.6 per year at Gombe. Allowing for a porportion of Tai predations occurring without being seen, this suggests that individual predation rates by Tai and Gombe males have similar magnitude, perhaps somewhat higher at Gombe.

Though no observational data are available for other sites, fecal analysis provides a relative measure of the frequency of meat-eating (i.e. including scavenging). Adequate samples (at least 500 feces) have been analyzed at three sites. Results indicate that Mahale and Mt. Assirik chimpanzees eat meat at comparable rates (proportion of feces containing mammalian remains: Mt. Assirik 1.8\%, $N=783$, McGrew, 1983; Mahale 1.9\%, $N=5,777$, data combined from Takahata et al., 1984 and UehaRA, 1986). In Gombe the proportion of feces with mammalian remains is about three times higher $(5.8 \%$ : June 1964-December 1967, $N=1,963$, MCGREw, 1983). Caution is required in interpreting these data because over time there can be considerable variation between samples at a single site. Thus for $\mathrm{M}$ group at Mahale the proportion of feces with mammalian remains has varied from $1.1 \%$ (June 1975-April 1982, $N=4,217$, TAKAHATA et al., 1984) to 5.9\% (September 1983February 1984, $N=1,053$, UeHARA, 1986), while between years at Gombe it varied from $1.5 \%(1967, N=525)$ to $13.8 \%(1964, N=456)$ (McGrew, 1983). Nevertheless the fecal data indicate that on average Gombe and Tai chimpanzees are more predatory than Mt. Assirik and Mahale chimpanzees. If the simplest assumptions are made about the relation between kill rate and proportion of feces containing mammal remains, it suggests that male kill rates in Mt. Assirik and Mahale are about one-third of the Gombe rate, i.e. of the order of four prey per year.

The highest kill rates by non-human primates have been recorded among baboons. STRUM (1981, Table 8.11) found that the mean number of observation hours between kills in the PHG troop at Gilgil varied between years from 12 to $22 \mathrm{hr}$. The highest predation rate was 
in 1973, when seven males accounted for $93 \%$ of 46 mammal kills (antelope fawns and hares) occurring once every $12 \mathrm{hr}$. At that rate each male would have killed an average of 49.0 prey per year. The rates of predation by Gombe and Tai chimpanzees are therefore not as high as the maximum recorded by non-human primates. Whether the long-term predation rates by any baboon population are as high as by chimpanzees in Gombe remains unclear.

\section{Amount of Meat Eaten by Chimpanzees}

Estimates of the amount of meat eaten depend on an unmeasured variable, the mean weight of prey. Adult female red colobus in Uganda weigh $7 \mathrm{~kg}$ (STRUHSAKER \& LeLAND, 1979), and infants weigh about 0.6-1.0 kg (Struhsaker, 1975). From August 1970 to April 1975 the size of prey was recorded for 62 kills: 30 were sized as infants, 16 juveniles, and 16 adults. By scoring infants as $1 \mathrm{~kg}$, juveniles as $4 \mathrm{~kg}$, and adults as $7 \mathrm{~kg}$, the mean weight of a colobus kill is estimated at $3.3 \mathrm{~kg}$. Hence, from 1972 to 1975 colobus kills provided an average of $(133.6 \times 3.3)=440.9 \mathrm{~kg}$ of carcass per year, varying from 213.9 to $907.8 \mathrm{~kg}$. All bushpigs killed were young. An estimate of $1.5 \mathrm{~kg}$ per kill indicates an annual supply of 50.6 $\mathrm{kg}$, ranging from 24.4 to $104.0 \mathrm{~kg}$. Thus these two species alone would have contributed $491.5 \mathrm{~kg}$ in an average year. Including meat from other mammals (Table 5), as well as birds and kills by females, the total annual supply would reach around $600 \mathrm{~kg}$. Almost all parts of prey animals are consumed (TELEKI, 1981). Distributed among 15 adult males, 19 adult females, and 20 infants and juveniles, this would give a mean of $11.1 \mathrm{~kg}$ per individual. Males eat more meat than females, however, and adults eat more than young (TELEKI, 1973). A more realistic distribution, therefore, would give $3 \mathrm{~kg}$ per offspring, $8 \mathrm{~kg}$ per female, and $25 \mathrm{~kg}$ per male in an average year, doubling to 6,16 , and $50 \mathrm{~kg}$ per year, respectively, in periods of high predation rates. Even this distribution across age-sex classes probably underestimates the proportion eaten by adult males on average, let alone by the most successful adult males.

There are no data on the weight of plant foods eaten by free-living chimpanzees. The proportion of food contributed by meat is therefore unknown. HiLL (1982) used the previous estimate of 63 kills per year by the Kahama and Kasekela communities to suggest that the percentage of daily calories provided by meat at Gombe was $3 \%$. Because this was outside the range observed among human foragers (12-86\% among seven populations), HiLL (1982) concluded that "all human hunter-gatherers get a much greater proportion of their daily food requirements from meat than do any other primates thus far reported." The upward revision of the meat intake of Gombe chimpanzees suggests the possibility of overlap between male chimpanzees and some foragers in the contribution of meat to the diet, though it certainly remains true that in general chimpanzees eat much less meat than human foragers. Nevertheless these results emphasize the adaptable nature of chimpanzee diets and show that meat can be much more than an occasional item. If australopithecines were regular meat-eaters that evolved from a chimpanzee-like ape, their adaptation to the savannah was not necessarily accompanied by any major change in predatory tendencies.

\section{Mortality Rates of Prey Species}

The rates of mortality clearly differed between prey species. The best data are on baboons and red colobus, both of which have been studied in Gombe and have large populations. 
Uncertainty about their population densities means that precise figures are not available, but the order of magnitude is clear in each case. The estimate of $1.1 \%$ of the baboon population killed by chimpanzees annually is well below the potential population growth rate, so that demographic effects are presumably slight.

However red colobus evidently sustain a remarkably high rate of predation. They were calculated here to lose $41.6 \%$ of their population to chimpanzee predation per year. Even if CLUTTON-BROCK's estimate of red colobus population density was half the true density, this would still mean that red colobus were killed at a rate of over $20 \%$ of their population per year. Furthermore these figures are based on the average rate from January 1972 to April 1975: from November 1973 to April 1975 the kill rate was double the average, suggesting that the predation rate on colobus would have increased correspondingly. Thus even the most conservative estimate implies that Gombe red colobus suffer one of the highest rates of predation known among primates. Although predation rates on primates are not well-known, estimates have been gathered from 30 populations (ChENEY \& Wrangham, 1987). The maximum estimated predation rates were $>15 \%$ ( $\%$ of population killed per year) (Galago senegalensis, Saguinus fuscicollis, and $S$. imperator). It is doubtful that a predation rate of $>40 \%$ of the population killed annually could be sustained.

BOESCH and BOESCH (1989) found that red colobus were the most frequent prey of chimpanzees $(77 \%, N=81)$ in Tai National Park. However the rate of predation appears lower than in Gombe. Thus based on BoESCH and BoEsCH's (1989) figures of 50 red colobus $/ \mathrm{km}^{2}$, 73.2 prey annually in the Tai community would represent 56.4 red colobus as prey in 27 $\mathrm{km}^{2}$, i.e. $2 / \mathrm{km}^{2}$ or $4 \%$ killed by chimpanzees per year.

Factors affecting vulnerability of Gombe species to chimpanzees were reviewed by TELEKI (1981). Red colobus were commonly caught in areas of broken canopy or isolated emergents offering few escape routes (e.g. in 13 out of 14 well-observed hunts, Wrangham, 1975). This suggested that in Gombe red colobus may be particularly vulnerable to chimpanzee predation because the tree canopy is relatively broken and open compared to typical forest habitats (ClutTon-Brock \& GilletT, 1979).

The idea that canopy structure is a good predictor of red colobus vulnerability to chimpanzees is supported by observations of groups of red colobus monkeys in Kibale Forest, Uganda, which vary considerably in their readiness to attack potential predators. Most react calmly to chimpanzees and humans, but three groups are particularly aggressive. All three live in heavily felled (i.e. broken canopy) forest, where they appear to be more vulnerable to predators than those living in closed canopy forest (GHIGLIERI, 1984; T. BUTYNSKI, pers. comm.). The fact that most red colobus in Kibale occupy closed canopy forest may partly explain what appears (BOESCH \& BOESCH, 1989) to be a low frequency of predation by chimpanzees there.

Further comparison between Gombe, Tai, and Kibale will help to clarify factors affecting the chimpanzee predation rate on red colobus. Meanwhile it is clear that although chimpanzees can be significant sources of mortality for both monkey and ungulate populations, the predation rate is poorly predicted by prey population density. Inter-populational differences in predation rates is also difficult to explain, as emphasized by BoESCH and BoEsCH's (1989) observation that Tai chimpanzees are much less easily deterred by red colobus aggression than are Gombe chimpanzees (or Kibale chimpanzees, G. I.-BASUTA, pers. comm.). Even when estimates of faunal density are available for australopithecines, therefore, reconstruction of their predation rates will not be easy. 
Acknowledgements. We are grateful to the Government of Tanzania for permission to work in Gombe National Park, and to J. Goodall and D. A. Hamburg for providing facilities. T. BuTYNSKI, K. HiLl, and T. STruhsaker and two anonymous reviewers kindly commented on an earlier draft.

Fieldwork was financed by the W. T. Grant Foundation.

\section{REFERENCES}

Albrecht, H. \& S. C. Dunnett, 1971. Chimpanzees in Western Africa. R. Piper \& Co., Munich. Anderson, J. R., E. A. Williamson, \& J. Carter, 1983. Chimpanzees of Sapo Forest, Liberia: density, nests, tools and meat-eating. Primates, 24: 594-601.

Azuma, S. \& A. Toyoshima, 1961-62. Progress report of the survey of chimpanzees in their natural habitat: Kabogo Point area, Tanganyika. Primates, 3(2): 61-70.

Boesch, C. \& H. Boesch, 1989. Hunting behavior of wild chimpanzees in the Tai National Park. Amer. J. Phys. Anthropol., 78: 547-573.

Busse, C. D., 1977. Chimpanzee predation as a possible factor in the evolution of red colobus monkey social organization. Evolution, 30: 907-911.

BUTYNSKI, T. M., 1982. Vertebrate predation by primates: a review of hunting patterns and prey. J. Human Evol., $11: 421-430$.

BygotT, D., 1972. Cannibalism among wild chimpanzees. Nature, 238: 410-411.

Cheney, D. L. \& R. W. Wrangham, 1987. Predation. In: Primate Societies, B. B. Smuts, D. L. Cheney, R. M. Seyfarth, R. W. Wrangham, \& T. T. Struhsaker (eds.), Univ. of Chicago Press, Chicago, pp. 227-239.

Clutton-Brock, T. H., 1972. Feeding and ranging behavior of the red colobus monkey. Ph.D. thesis, Univ. of Cambridge, Cambridge.

_ \& J. B. Gillett, 1979. A survey of forest composition in the Gombe National Park, Tanzania. Afr. J. Ecol., 17: 131-158.

de Bournonville, D., 1967. Contribution a l'étude du chimpanzé en Republique de Guinée. Bull. Inst. Fond. Afr. Noire, 29: 1188-1269.

Dupuy, A. R., 1970. Sur la présence du chimpanzé dans les limites du Parc National du NiokolaKoba (Sénégal). Bull. Inst. Fond. Afr. Noire, 32: 1090-1099.

Ghigleri, M. P., 1984. The Chimpanzees of Kibale Forest: A Field Study of Ecology and Social Structure. Columbia Univ. Press, New York.

Goodall, J., 1963. Feeding behavior of chimpanzees: a preliminary report. Synip. Zool. Soc. London, 10: $39-48$.

- , 1968. The behavior of free-living chimpanzees in the Gombe Stream Reserve. Anim. Behav. Monogr., 1: 161-311.

- 1986. The Chimpanzees of Gombe: Patterns of Behavior. Harvard Univ. Press, Cambridge.

Hasegawa, T., M. Hiraiwa, T. Nishida, \& H. Takasaki, 1983. New evidence on scavenging behavior in wild chimpanzees. Cur. Anthropol., 24: 231-232.

Hill, K., 1982. Hunting and human evolution. J. Human Evol., 11: 521-544.

Hladik, C. M., 1973. Alimentation et activité d'un groupe de chimpanzés reintroduits en forêt gabonaise. La Terre et la Vie, $27: 343-413$.

IzAWA, K., 1970. Unit-groups of chimpanzees and their nomadism in the savannah woodland. Primates, $11: 1-46$.

- \& J. ITANI, 1966. Chimpanzees in Kasakati Basin, Tanganyika. (1) Ecological studies in the rainy season, 1963-1964. Kyoto Univ. Afr. Stud., 1: 73-156.

Jones, C. \& J. Sabater Pi, 1971. Comparative Ecology of Gorilla gorilla (SAvage \& WyMaN) and Pan troglodytes (Blumenbach) in Rio Muni, West Africa. Bibliotheca Primatologica, Vol. 13, Karger, Basel.

Kano, T., 1971. The chimpanzee of Filabanga, Western Tanzania. Primates, 12: 229-246.

Kortlandt, A., 1962. Chimpanzees in the wild. Sci. Amer., 206: 128-138.

MCGREW, W. C., 1979. Evolutionary implications of sex differences in chimpanzee predation and tool use. In: The Great Apes, D. A. Hamburg \& E. R. McCown (eds.), Benjamin/Cummings, Menlo Park, pp. 441-463.

, 1983. Animal foods in the diets of wild chimpanzees (Pan troglodytes): why cross-cultural variation? J. Ethol., 1:46-61. 
C. E. G. Tutin, \& P. J. BALDwin, 1978. Primates preying upon vertebrates: new records from West Africa. Carnivore, 1: 41-45.

thropol., 20: 238-239.

$\&-, 1979$. New data on meat-eating by wild chimpanzees. Cur. An-

Morris, K. \& J. Goodall, 1977. Competition for meat between chimpanzees and baboons of the Gombe National Park, Folia Primatol., 28: 109-121.

Nishida, T., 1989. A note on the chimpanzee ecology of the Ugalla area, Tanzania. Primates, 30: 129-138.

S. Uehara, \& R. Nyundo, 1979. Predatory behavior among wild chimpanzees of the Mahale Mountains. Primates, 20: 1-20.

Nissen, H. W., 1931. A field study of the chimpanzee. Comp. Psychol. Monogr., 8: 1-122.

Reynolds, V.\& F. Reynolds, 1965. Chimpanzees of the Budongo Forest. In: Primate Behavior, I. DeVore (ed.), Holt, Rinehart, \& Winston, New York, pp. 368-424.

Struhsaker, T. T., 1975. The Red Colobus Monkey. Univ. of Chicago Press, Chicago.

- \& L. LeLAND, 1979. Socioecology of five sympatric monkey species in the Kibale Forest, Uganda. Adv. Stud. Behav., 9: 159-227.

Strum, S. C., 1981. Processes and products of change: baboon predatory behavior at Gilgil, Kenya. In: Omnivorous Primates: Gathering and Hunting in Human Evolution, R. S. O. HARdING \& G. Teleki (eds.), Columbia Univ. Press, New York, pp. 255-302.

SugiYama, Y., 1981. Observations on the population dynamics and behavior wild chimpanzees at Bossou, Guinea, in 1979-1980. Primates, 22: 435-444.

SUzUKI, A., 1975. The origin of hominid hunting: a primatological perspective. In: Socioecology and Psychology of Primates, R. H. TutTle (ed.), Mouton, The Hague, pp. 259-278.

Takahata, Y., T. Hasegawa, \& T. Nishida, 1984. Chimpanzee predation in the Mahale Mountains from August 1979 to May 1982. Int. J. Primatol., 5: 213-233.

TeleKI, G., 1973. The Predatory Behavior of Wild Chimpanzees. Bucknell Univ. Press, Lewisburg, Pennsylvania.

__, 1981 . The omnivorous diet and electric feeding habits of chimpanzees in Gombe National Park, Tanzania. In: Omnivorous Primates: Gathering and Hunting in Human Evolution, R. S. O. Harding \& G. Teleki (eds.), Columbia Univ. Press, New York, pp. 303-343.

Uehara, S., 1986. Sex and group differences in feeding on animals by wild chimpanzees in the Mahale Mountains National Park, Tanzania. Primates, 27: 1-13.

Wrangham, R. W., 1974. Artificial feeding of chimpanzees and baboons in their natural habitat. Anim. Behav., 22: 83-93.

1975. The behavioral ecology of chimpanzees in Gombe National Park, Tanzania. Ph.D. thesis, Cambridge Univ., Cambridge.

- 1977. Feeding behavior of chimpanzees in Gombe National Park, Tanzania. In: Primate Ecology, T. H. Clutton-Brock (ed.), Academic Press, London, pp. 503-508.

- Received August 21, 1987; Accepted August 7, 1989

Authors' Names and Present Addresses: R. W. Wrangham, Department of Anthropology, Peabody Museum, Harvard University, Cambridge, Massachusetts 02138, U.S.A.; E. VAN ZinnicQ Bergmann Riss, Box 189. Madison, New Hampshire 03489, U.S.A. 